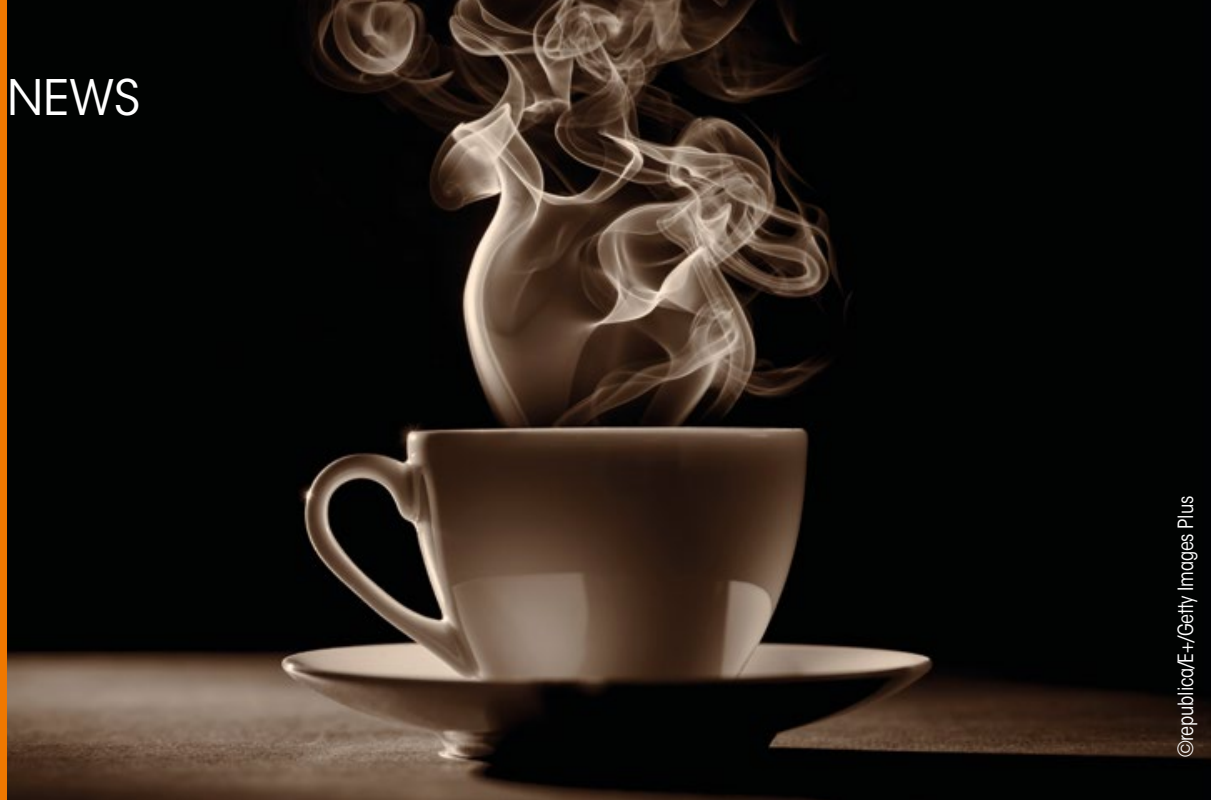

\section{HOT DRINK LINK TO OESOPHAGEAL CANCER}

Very hot drinks may be linked to a $90 \%$ higher risk of getting cancer of the oesophagus, a large study suggests. Drinking $700 \mathrm{ml}$ of tea at $60 \mathrm{C}(140 \mathrm{~F})$ or higher was "consistently associated" with the increased risk compared with people who had drinks at a lower temperature. The drinking habits of 50,045 people aged 40 to 75 , living in north-eastern Iran, were monitored by scientists. Some 317 new cases of the cancer were found during a follow-up period from 2004 to 2017. Lead author Dr Farhad Islam, of the American Cancer Society, said it is 'advisable to wait until hot beverages cool down before drinking.

'As long you're letting your tea cool down a bit before you drink it, or adding cold milk, you're unlikely to be raising your cancer risk, he said. The study - published in the International Journal of Cancer backs up the World Health Organisation, which in 2016 said drinks above 65C (149F) were a probable carcinogen.

\title{
Netflix documentary condemmed by dental profession
}

A documentary film called Root Cause has been removed from the streaming service Netflix after being widely criticised by dental organisations worldwide. The feature length documentary film revived the theories promulgated by the now discredited Weston Price whose focal infection theory questioned the safety of root canal treatments.

In the 1920s, Weston Price blamed endodontic treatment for a variety of systemic diseases and argued it was preferable to extract teeth.

From time to time his theories have been resurrected and then swiftly debunked. The decision by Netflix to create and air their programme has been condemned by many organisations. The British Endodontic Society responded by adding information to the news page ${ }^{1}$ of its website under the heading Exploding Endodontic Myths and linking to a position statement from the European Society of Endodontology. This said the movie put forward 'unfounded and malicious' claims and that root canal treatment is one of the best documented and safest procedures for preventing and curing oral infections and thus prevent and treat rather than cause systemic complications.

The BDA sent an email to members in which it warned the film was 'propagating misinformation about systemic health problems supposedly caused by root canal treatment.

The BDA advised its members that if they encountered any concerns from patients, they could refer them to a patient leaflet. ${ }^{2}$

\section{References}

1. https://britishendodonticsociety.org.uk/ news/current-news (accessed March 2019)

2. BDA. Patient Leaflets - Endodontic (root canal) treatment (2018). http://bda-mail. org/FS/2323/Documents/Research\%20 and\%20Policy/PL17\%20-\%20ROOT\%20 CANAL\%20TREATMENT\%20WEB. PDF. (accessed March 2019).

\section{A wake up call to vapers}

Vaping is linked to a greater risk of heart attack, according to research presented at the annual meeting of the American College of Cardiology. Researchers from the University of Kansas found e-cigarette users were 34 percent more likely to have a heart attack and 25 percent more likely to have coronary artery disease. They were also 55 percent more likely to suffer from depression or anxiety. The associations held true even when controlling for other known cardiovascular risk factors, such as age, sex, body mass index, high cholesterol, high blood pressure and smoking. Although the researchers said they were also unable to determine whether the damage had occurred prior to using e-cigarettes, or was caused by vaping, they said the study should provide a 'wake up call' for people who consider the practice to be safe.

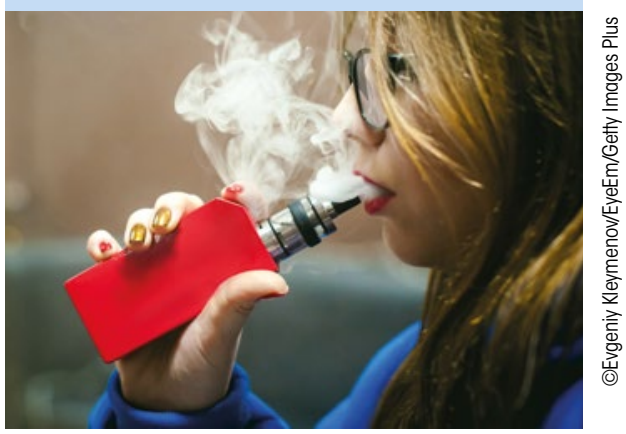

\section{NHS DENTAL CHARGES RISE BY 5\%}

The cost of a dental check-up is set to rise by $£ 1.10$ as part of a package of increases announced by the Government last month. Band one charges, which include check-ups will be rising from $£ 21.60$ to $£ 22.70$, Band two charges will rise by $£ 3$ from $£ 59.10$ to

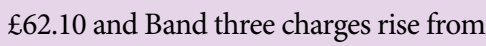
$£ 256.50$ to $£ 269.30$. The British Dental Association has condemned the $5 \%$ hike in NHS dental costs. The BDA's Chair of General Dental Practice Henrik OvergaardNielsen said: 'These inflation-busting hikes don't put a penny of new investment into this service, and will do nothing for patients unable to find an appointment, or the practices struggling to recruit staff.' 